\title{
The Mouse (Mus musculus)T Cell Receptor Beta Variable (TRBV), Diversity (TRBD) and Joining (TRBJ) Genes
}

\author{
Nathalie Bosc Marie-Paule Lefranc \\ Laboratoire d'ImmunoGénétique Moléculaire, Institut de Génétique Humaine, CNRS, \\ Université Montpellier II, Montpellier, France
}

\section{Key Words}

Mouse genes · IMGT · T cell receptor · Beta variable regions $\cdot$ Beta diversity regions .

Beta joining regions

\begin{abstract}
'The Mouse (Mus musculus) T cell Receptor Beta Variable (TRBV), Diversity (TRBD), and Joining (TRBJ) Genes', the 14th report of the 'IMGT Locus in Focus' section, comprises 8 tables entitled: (1) 'Number of mouse (Mus musculus) germline TRBV genes at $6 \mathrm{~A}-\mathrm{C}$ and potential repertoire'; (2) 'Mouse (Mus musculus) germline TRBV genes at $6 \mathrm{~A}-\mathrm{C}^{\prime}$; (3) 'Mouse (Mus musculus) TRBV allele table'; (4) 'Mouse (Mus musculus) germline TRBD genes and alleles'; (5) 'Mouse (Mus musculus) germline TRBJ genes'; (6) 'Mouse (Mus musculus) TRBJ allele table'; (7) 'Correspondence between the different mouse (Mus musculus) TRBV gene nomenclatures'; (8) 'Mouse (Mus musculus) TRBV genes and related human TRBV genes'. These tables are
\end{abstract}

\begin{tabular}{ll}
\hline KARGER & ( ) 2000 S. Karger AG, Basel \\
Fax +41 61 306 1234-9670/00/0174-0216\$17.50/0 \\
$\begin{array}{l}\text { E-Mail karger@karger.ch } \\
\text { www.karger.com }\end{array}$ & $\begin{array}{l}\text { Accessible online at: } \\
\text { www.karger.com/journals/eci }\end{array}$
\end{tabular}

available at the IMGT Marie-Paule page from IMGT, the international ImMunoGeneTics database (http://imgt.cines.fr:8104) created by Marie-Paule Lefranc, Université Montpellier II, CNRS, Montpellier, France.

Copyright (@) 2000 S. Karger AG, Basel

\section{Introduction}

'The Mouse (Mus musculus) T cell Receptor Beta Variable (TRBV), Diversity (TRBD) and Joining (TRBJ) Genes' is the 14th report of the 'IMGT Locus in Focus' section launched in the April 1998 issue of Experimental and Clinical Immunogenetics [1-14]. The complete repertoire of the human germline TRBV, TRBD and TRBJ genes has previously been reported [8, 11, 14]. This 14 th report on the mouse (Mus musculus) $\mathrm{T}$ cell receptor beta variable, diversity and joining genes describes, for the first time, the complete murine germline TRB repertoire, with the same standardized rules of the IMGT scientific chart [15]

Prof. Marie-Paule Lefranc, IMGT, Laboratoire d'Immuno Génétique Moléculaire, LIGM, UPR CNRS 1142, IGH, 141 rue de la Cardonille F-34396 Montpellier Cedex 5 (France)

Tel. +33499619965, Fax +33499619901

E-Mail lefranc@ligm.igh.cnrs.fr, IMGT: http://imgt.cines.fr:8104 
which were used for the description of the human TRB repertoire $[8,11,14]$. This report comprises 8 tables entitled: (1) 'Number of mouse (Mus musculus) germline TRBV genes at 6A-C and potential repertoire'; (2) 'Mouse (Mus musculus) germline TRBV genes at 6AC'; (3) 'Mouse (Mus musculus) TRBV allele table'; (4) 'Mouse (Mus musculus) germline TRBD genes and alleles'; (5) 'Mouse (Mus musculus) germline TRBJ genes'; (6) 'Mouse
(Mus musculus) TRBJ allele table'; (7) 'Correspondence between the different mouse (Mus musculus) TRBV gene nomenclatures'; (8) 'Mouse (Mus musculus) TRBV genes and related human TRBV genes'. These tables are available at the IMGT Marie-Paule page from IMGT, the international ImMunoGeneTics database (http://imgt.cines.fr:8104) created by Marie-Paule Lefranc, Université Montpellier II, CNRS, Montpellier, France $[15,16]$.

Table 1. Number of mouse (Mus musculus) germline TRBV genes at $6 \mathrm{~A}-\mathrm{C}$ and potential repertoire

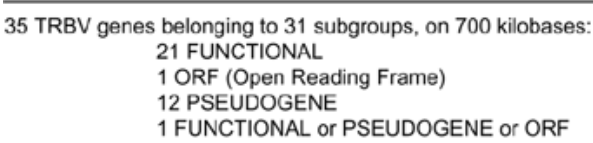

Potential repertoire: 21-22 FUNCTIONAL TRBV genes belonging to 19 subgroups

\begin{tabular}{|c|c|c|c|c|}
\hline Subgroup & Functional & ORF & Pseudogene & Total \\
\hline TRBV1 & 1 & - & - & 1 \\
\hline TRBV2 & 1 & - & - & 1 \\
\hline TRBV3 & 1 & - & - & 1 \\
\hline TRBV4 & 1 & - & - & 1 \\
\hline TRBV5 & 1 & - & - & 1 \\
\hline TRBV6 & - & - & 1 & 1 \\
\hline TRBV7 & - & - & 1 & 1 \\
\hline TRBV8 & - & - & 1 & 1 \\
\hline TRBV9 & - & - & 1 & 1 \\
\hline TRBV10 & - & - & 1 & 1 \\
\hline TRBV11 & - & - & 1 & 1 \\
\hline TRBV12 & 2 & - & 1 & 3 \\
\hline TRBV13 & 3 & - & - & 3 \\
\hline TRBV14 & 1 & - & - & 1 \\
\hline TRBV15 & 1 & - & - & 1 \\
\hline TRBV16 & 1 & - & - & 1 \\
\hline TRBV17 & 1 & - & - & 1 \\
\hline TRBV18 & - & - & 1 & 1 \\
\hline TRBV19 & 1 & - & - & 1 \\
\hline TRBV20 & 1 & - & - & 1 \\
\hline TRBV21 & - & 1 & - & 1 \\
\hline TRBV22 & - & - & 1 & 1 \\
\hline TRBV23 & 1 & - & - & 1 \\
\hline TRBV24 & $(1)^{*}$ & $(1)^{*}$ & $(1)^{*}$ & 1 \\
\hline TRBV25 & - & - & 1 & 1 \\
\hline TRBV26 & 1 & - & - & 1 \\
\hline TRBV27 & - & - & 1 & 1 \\
\hline TRBV28 & - & - & 1 & 1 \\
\hline TRBV29 & 1 & - & - & 1 \\
\hline TRBV30 & 1 & - & - & 1 \\
\hline TRBV31 & 1 & - & - & 1 \\
\hline Total & $21(+1)^{*}$ & $1(+1)^{*}$ & $12(+1)^{*}$ & 35 \\
\hline & & & & \\
\hline TRB & & & & 1 \\
\hline
\end{tabular}

*FUNCTIONAL Or PSEUDOGENE or ORF (TRBV24)

Author: Nathalie Bosc imgt@ligm.igh.cnrs.fr 


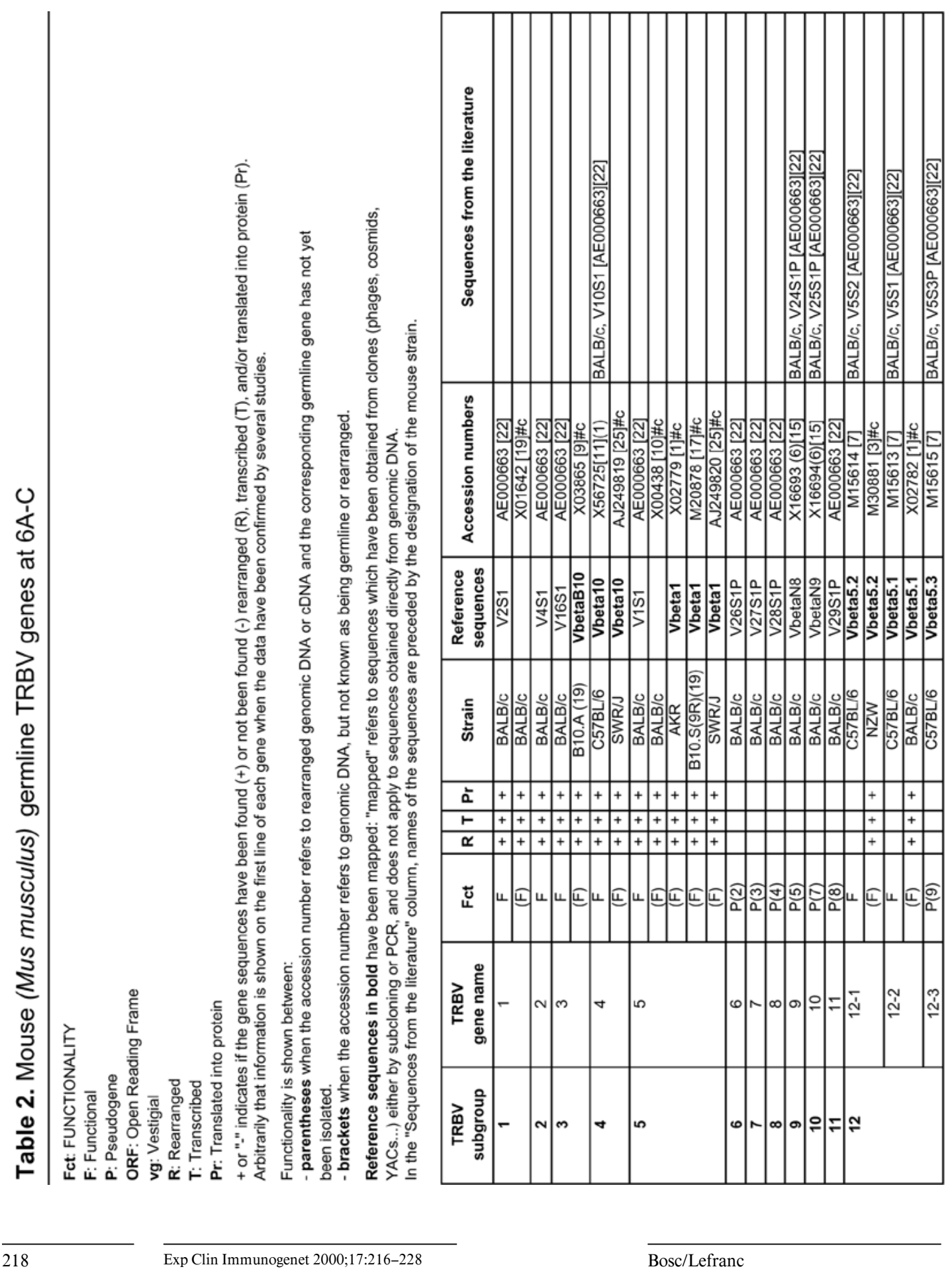




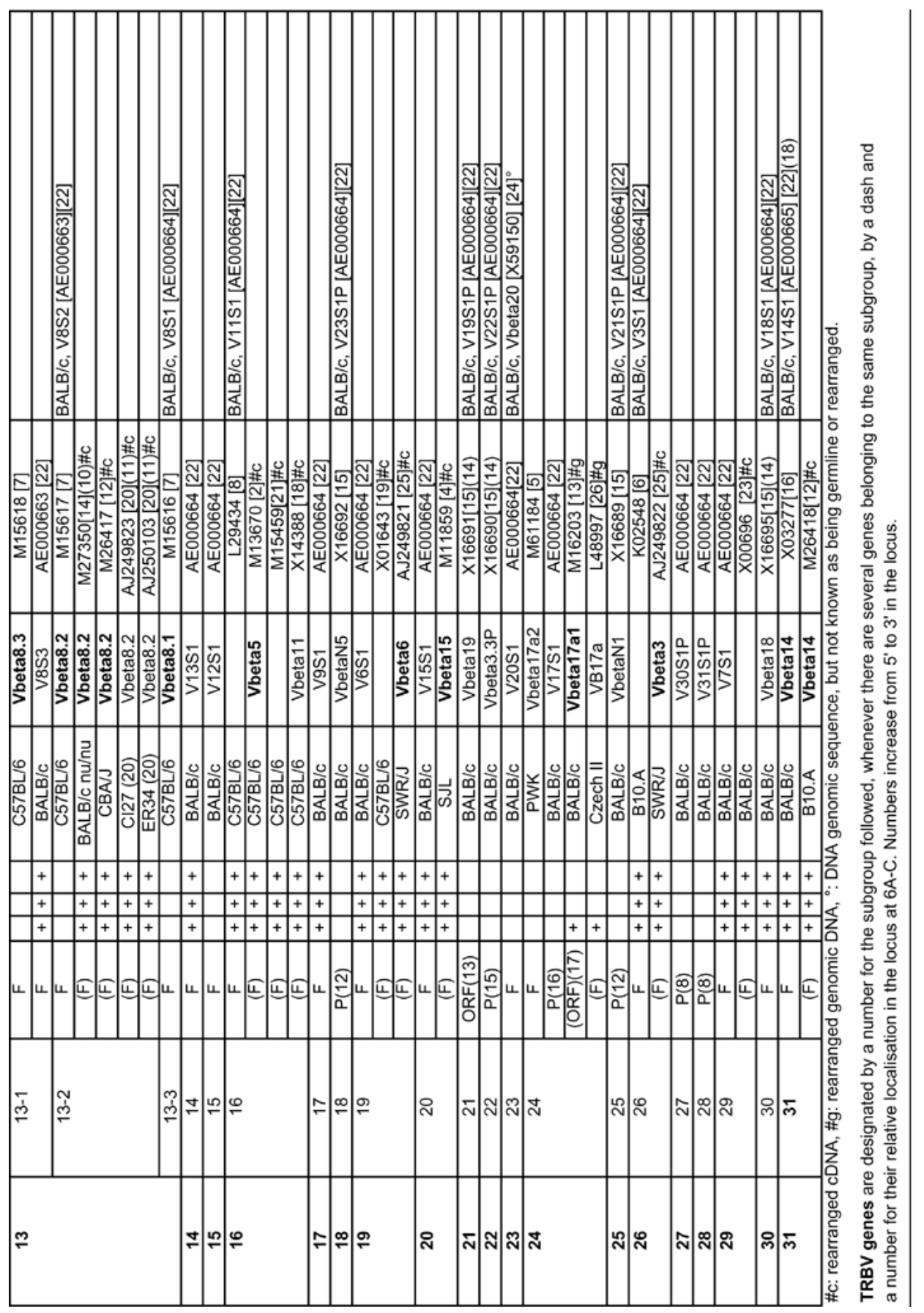

Mouse TRBV, TRBD and TRBJ Genes

Exp Clin Immunogenet 2000;17:216-228 


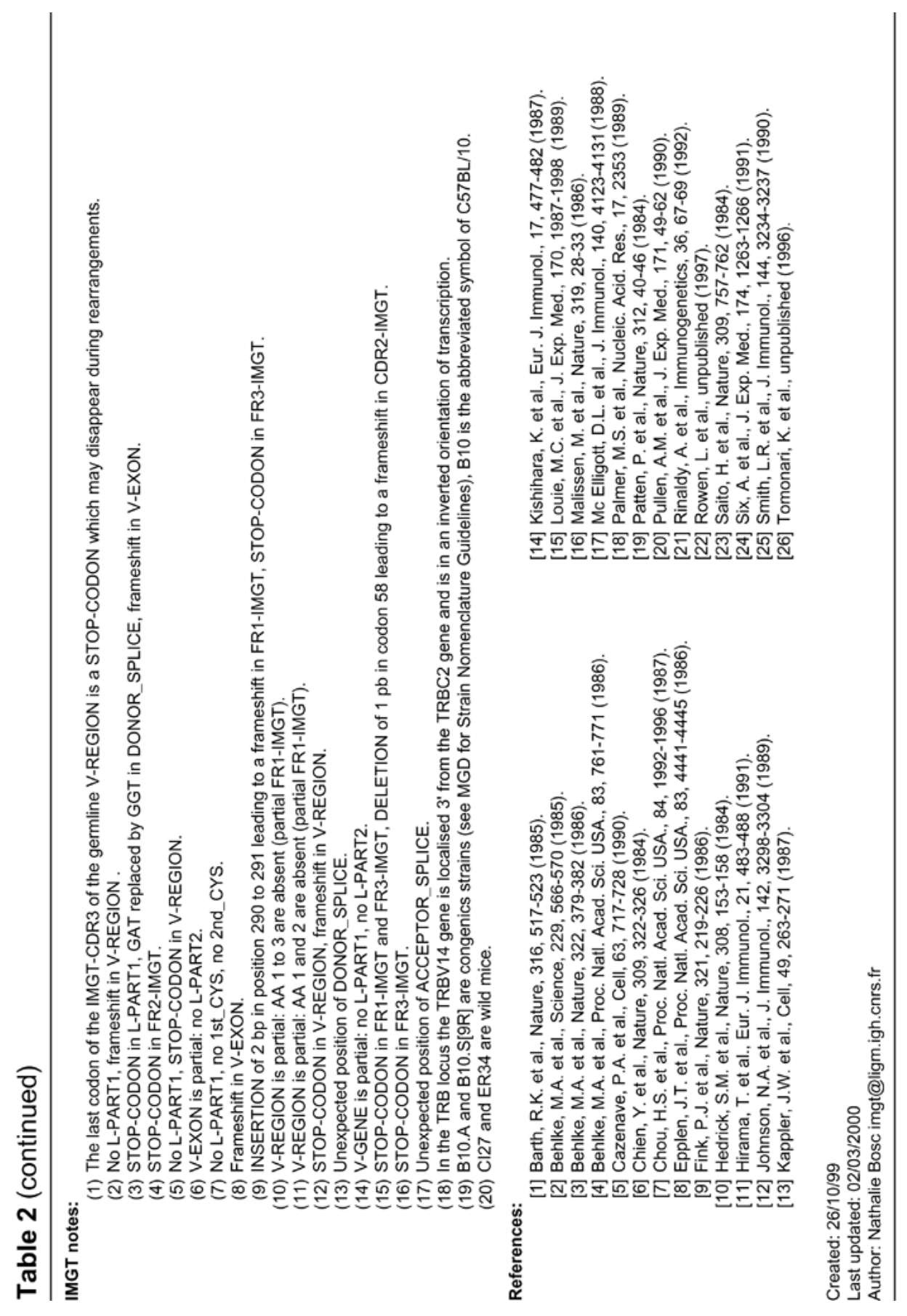




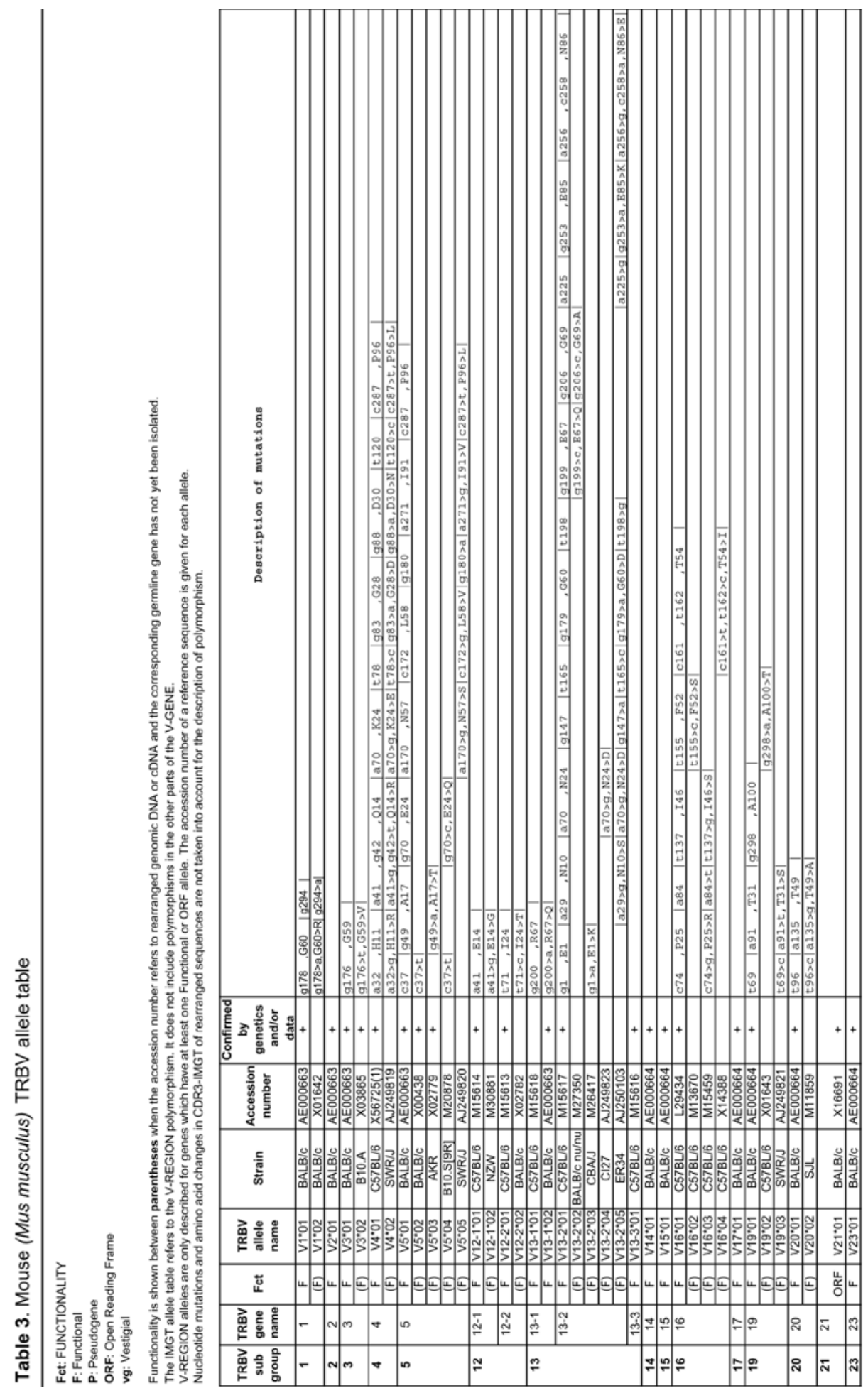

Mouse TRBV, TRBD and TRBJ Genes

Exp Clin Immunogenet 2000;17:216-228 

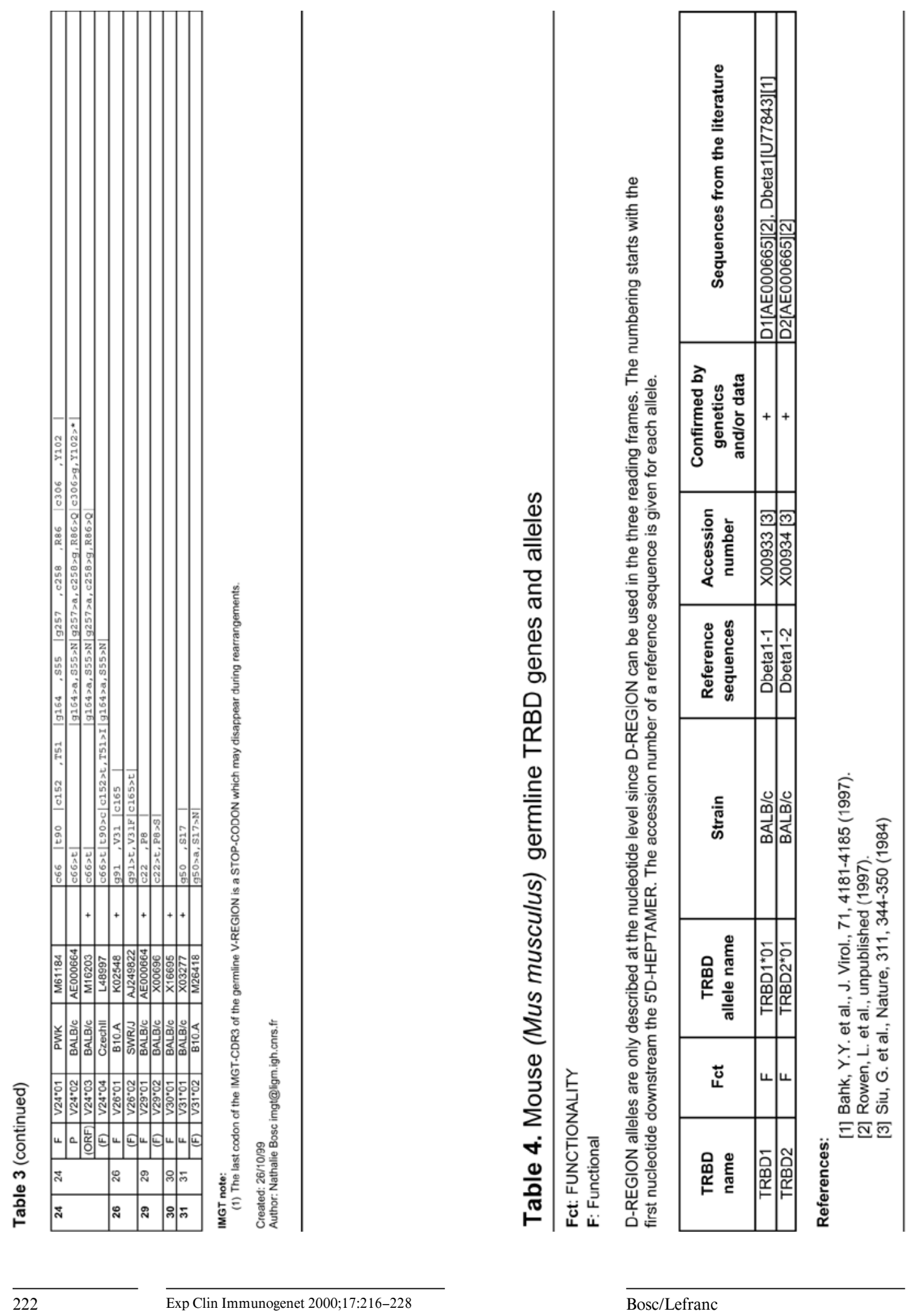

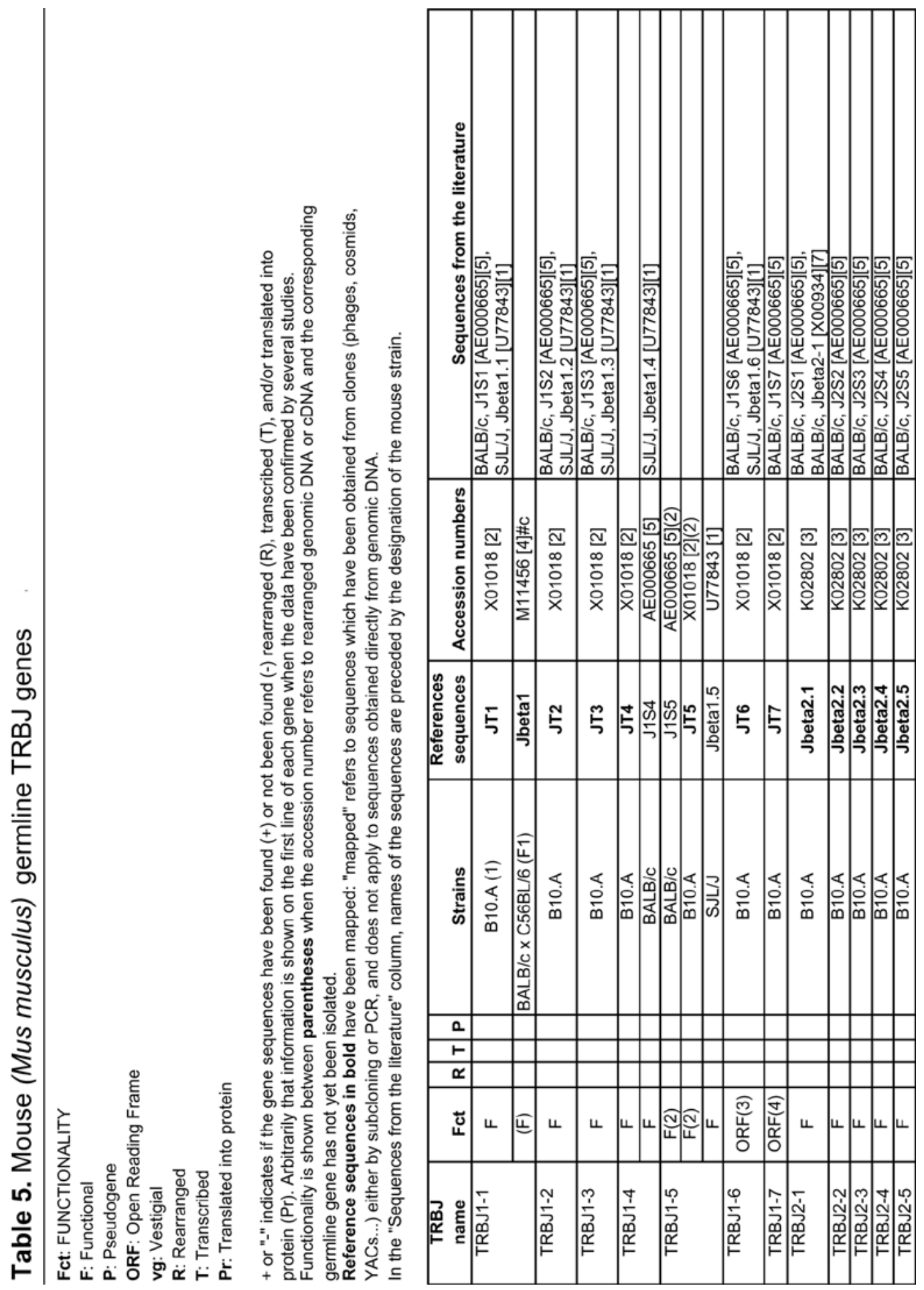

Mouse TRBV, TRBD and TRBJ Genes

Exp Clin Immunogenet 2000;17:216-228 


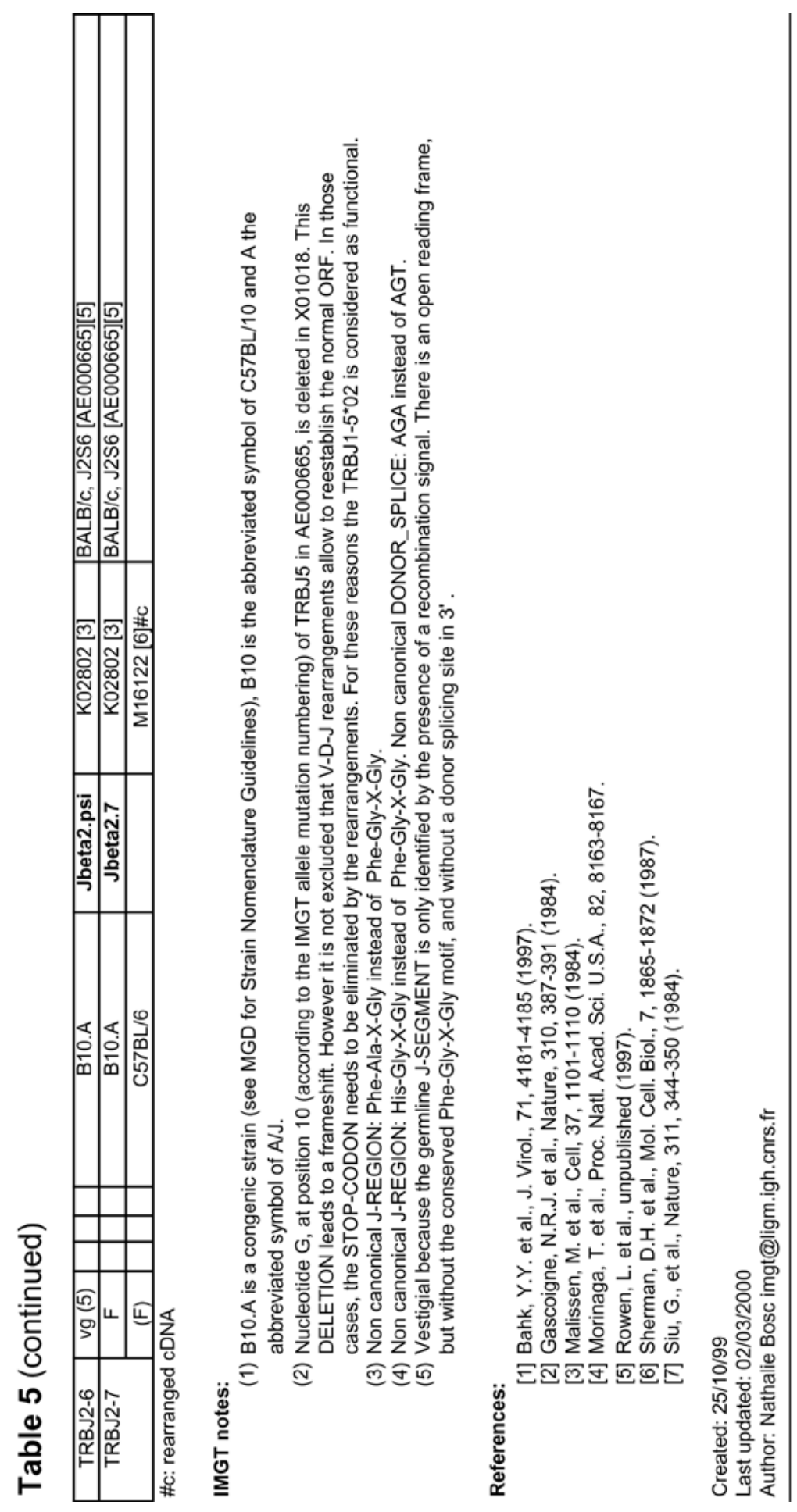

224

Exp Clin Immunogenet 2000;17:216-228

Bosc/Lefranc 


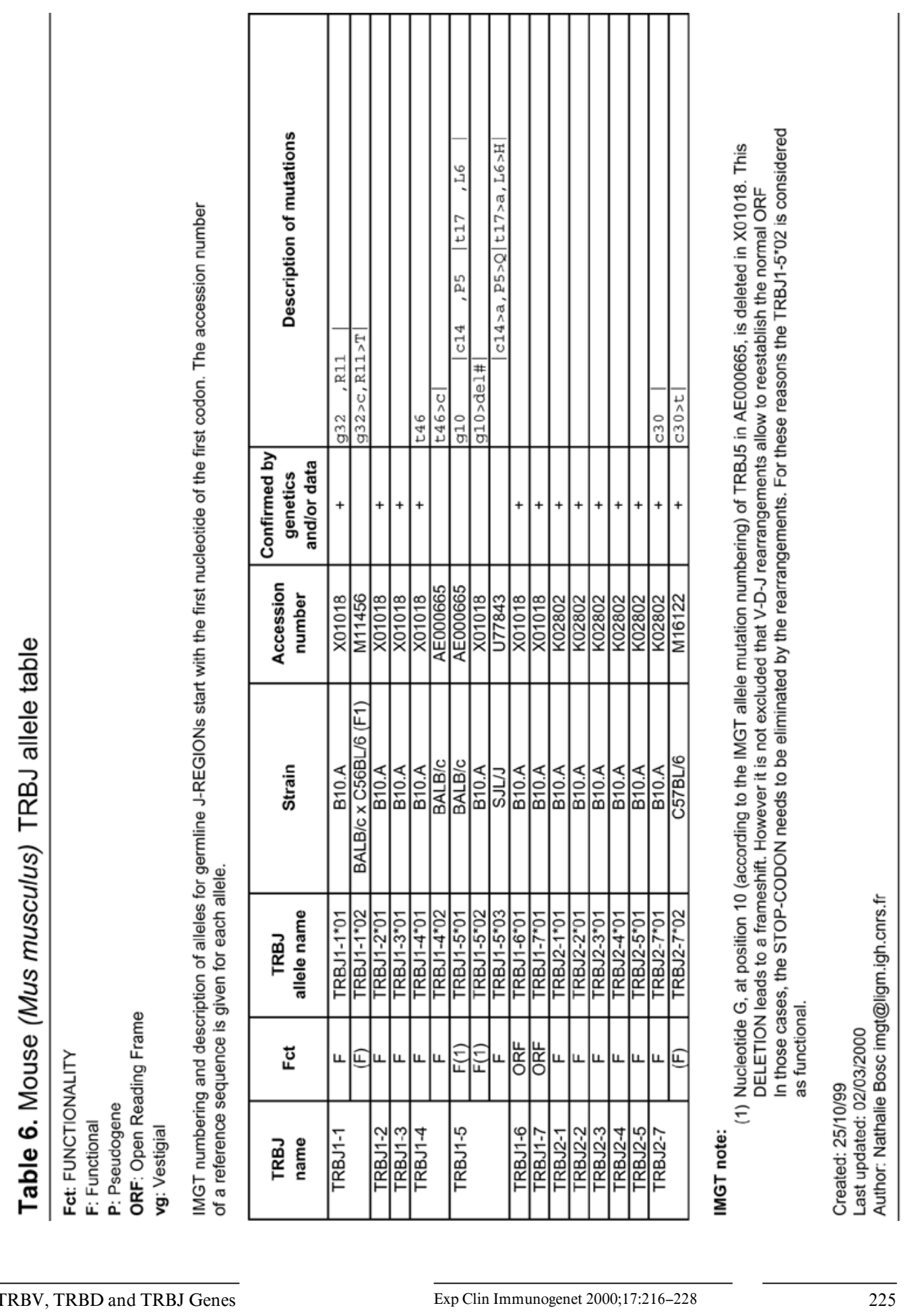


Table 7. Correspondence between the different mouse (Mus musculus) TRBV gene nomenclatures

Mouse TRBV genes are listed from $3^{\prime}$ (top of the table) to $5^{\prime}$ (bottom of the table) in the TRB locus at 6A-C.

\begin{tabular}{|c|c|c|}
\hline $\begin{array}{c}\text { IMGT TRBV } \\
\text { gene name }[1](1)\end{array}$ & Wilson, R.K. et al [2] & Arden, B. et al. [3] \\
\hline$\overline{31}$ & 14 & $14 \mathrm{S1}$ \\
\hline 30 & $18(2)$ & $18 \mathrm{~S} 1$ \\
\hline 29 & 7 & $7 \mathrm{S1}$ \\
\hline 28 & & $31 \mathrm{~S} 1$ \\
\hline 27 & & $30 S 1$ \\
\hline 26 & 3.1 & $3 \mathrm{S1}$ \\
\hline 25 & & $21 \mathrm{S1}$ \\
\hline 24 & 17 & 17S1 \\
\hline 23 & $20(3)$ & $20 S 1$ \\
\hline 22 & & $22 \mathrm{~S} 1$ \\
\hline 21 & 19 & $19 S 1$ \\
\hline 20 & 15 & $15 \mathrm{~S} 1$ \\
\hline 19 & 6 & $6 \mathrm{~S} 1$ \\
\hline 18 & & $23 \mathrm{~S} 1$ \\
\hline 17 & 9 & 9S1 \\
\hline 16 & 11 & 11S1 \\
\hline 15 & 12 & $12 \mathrm{~S} 1$ \\
\hline 14 & 13 & $13 S 1$ \\
\hline $13-3$ & 8.1 & $8 \mathrm{~S} 1$ \\
\hline $13-2$ & 8.2 & $8 \mathrm{~S} 2$ \\
\hline $13-1$ & 8.3 & $8 \mathrm{S3}$ \\
\hline $12-3$ & 5.3 & 5 S3 \\
\hline $12-2$ & 5.1 & $5 \mathrm{~S} 1$ \\
\hline $12-1$ & 5.2 & $5 \mathrm{~S} 2$ \\
\hline 11 & & $29 S 1$ \\
\hline 10 & & $25 \mathrm{~S} 1$ \\
\hline 9 & & $24 S 1$ \\
\hline 8 & & $28 \mathrm{S1}$ \\
\hline 7 & & $27 S 1$ \\
\hline 6 & & $26 \mathrm{S1}$ \\
\hline 5 & 1 & $1 \mathrm{S1}$ \\
\hline 4 & 10 & $10 \mathrm{~S} 1$ \\
\hline 3 & 16 & $16 \mathrm{~S} 1$ \\
\hline 2 & 4 & 4S1 \\
\hline 1 & 2 & $2 \mathrm{~S} 1$ \\
\hline
\end{tabular}

IMGT notes:

(1) Mouse TRBV genes are designated by a number for the subgroup followed, whenever there are several genes belonging to the same subgroup, by a dash and a number for their relative localisation in the TRB locus at $6 \mathrm{~A}-\mathrm{C}$.

(2) defined in [4]

(3) defined in [5

References:

[1] Bosc, N. and Lefranc, M.-P., In IMGT Repertoire, http://imgt.cines.fr:8104, created 22/07/1999, and this paper.

[2] Wilson, R.K. et al., Immunol. Rev., 101, 149-172 (1988)

[3] Arden, B. et al., Immunogenetics, 42, 455-500 (1995)

[4] Louie, M.C. et al., J. Exp. Med., 170, 1987-1998 (1989)

[5] Six, A. et al., J. Exp. Med., 174, 1263-1266 (1991) 
Table 8. Mouse (Mus musculus) TRBV genes and related human TRBV genes

Mouse and humanTRBV genes are listed from $3^{\prime}$ (top of the table) to $5^{\prime}$ (bottom of the table) in their respective TRB loci at 6A-C, and 7q35.

\begin{tabular}{|l|l|}
\hline Mouse IMGT TRBV & Related human IMGT TRBV \\
\hline
\end{tabular} genes [1] (1) $\quad$ genes [2]

\begin{tabular}{|c|c|}
\hline genes [1] (1) & genes [2] \\
\hline 31 & 30 \\
\hline 30 & $29-1$ \\
\hline 29 & 28 \\
\hline & 27 \\
\hline & 26 \\
\hline & $25-1$ \\
\hline
\end{tabular}

\begin{tabular}{|c|c|}
\hline & $25-1$ \\
\hline 28 & $24-1$ \\
\hline 27 & \\
\hline 26 & $23-1$ \\
\hline 25 & \\
\hline 24 & \\
\hline 23 & 22 \\
\hline 22 & \\
\hline
\end{tabular}

\begin{tabular}{|c|c|}
\hline 22 & $21-1$ \\
\hline 21 & $20-1$ \\
\hline 20 & \\
\hline 19 & 19 \\
\hline & 18 \\
\hline 18 & 17 \\
\hline & 16 \\
\hline 17 & 15 \\
\hline & 14 \\
\hline 16 & 13 \\
\hline
\end{tabular}

\begin{tabular}{|c|c|}
\hline & 13 \\
\hline 16 & $12-1$ to $12-5$ \\
\hline 15 & $11-1$ to $11-3$ \\
\hline 14 & $10-1$ to $10-3$ \\
\hline $13-2$ & \\
\hline $13-1$ & \\
\hline $12-3$ & \\
\hline $12-2$ & 9 \\
\hline & \\
\hline & \\
\hline & \\
\hline & \\
\hline & \\
\hline
\end{tabular}

IMGT notes:

\begin{tabular}{|c|c|}
\hline & \\
\hline & $8-1,8-2$ \\
\hline & $7-1$ to $7-9$ \\
\hline \multicolumn{2}{|l|}{$\frac{11}{10}$} \\
\hline & 10 \\
\hline \multirow{2}{*}{\multicolumn{2}{|c|}{$\frac{9}{8}$}} \\
\hline & \\
\hline & $6-1$ to $6-9$ \\
\hline & $5-1$ to $5-8$ \\
\hline \multicolumn{2}{|l|}{7} \\
\hline \multicolumn{2}{|l|}{6} \\
\hline & $4-1$ to $4-3$ \\
\hline \multicolumn{2}{|l|}{5} \\
\hline \multirow[t]{3}{*}{4} & $3-1,3-2$ \\
\hline & 2 \\
\hline & 3 \\
\hline & 1 \\
\hline \multicolumn{2}{|l|}{2} \\
\hline \multicolumn{2}{|l|}{1} \\
\hline & $\mathrm{A}$ \\
\hline & $\mathrm{B}$ \\
\hline
\end{tabular}

(1) Mouse and human TRBV genes are designated by a number for the subgroup followed. whenever there are several genes belonging to the same subgroup, by a dash and a number for their relative localisation in their respective loci at $6 \mathrm{~A}-\mathrm{C}$, and $7 \mathrm{q} 35$.

References:

[1] Bosc, N. and Lefranc, M.-P., In IMGT Repertoire, http://imgt.cines.fr:8104, created 22/07/1999, and

this paper.
[2] Folch, G. and Lefranc, M.-P., Exp. Clin. Immunogenet., 17, $42-54$ (2000) 


\section{Acknowledgments}

We thank Valérie Contet for contribution to the manuscript and Gérard Lefranc for helpful discussion. IMGT is funded by the European Union's BIOTECH programme (BIO4CT96-0037), the Centre National de la Recherche Scientifique, the Ministère de l'Educa- tion Nationale, and the Ministère de la Recherche. Subventions have been received from the Association pour la Recherche sur le Cancer, Association de la Recherche sur la Polyarthrite, Fondation pour la Recherche Médicale, Ligue Nationale contre le Cancer and the Région Languedoc-Roussillon.

\section{References}

1 Lefranc MP: IMGT locus on focus: A new section of Experimental and Clinical Immunogenetics. Exp Clin Immunogenet 1998;15:1-7.

2 Pallarès N, Frippiat JP, Giudicelli V, Lefranc MP: The human immunoglobulin lambda variable (IGLV) genes and joining (IGLJ) segments. Exp Clin Immunogenet 1998;15:818.

3 Barbié V, Lefranc MP: The human immunoglobulin kappa variable (IGKV) genes and joining (IGKJ) segments. Exp Clin Immunogenet 1998:15:171-183.

4 Martinez C, Lefranc MP: The mouse (Mus musculus) immunoglobulin kappa variable (IGKV) genes and joining (IGKJ) segments. Exp Clin Immunogenet 1998;15: 184-193.

5 Pallarès N, Lefebvre S, Contet V, Matsuda F, Lefranc MP: The human immunoglobulin heavy variable (IGHV) genes. Exp Clin Immunogenet 1999;16:36-60.
6 Ruiz M, Pallarès N, Contet V, Barbié V, Lefranc MP: The human immunoglobulin heavy diversity (IGHD) and joining (IGHJ) segments. Exp Clin Immunogenet 1999;16:173-184.

7 Scaviner D, Barbié V, Ruiz M, Lefranc MP: Protein displays of the human immunoglobulin heavy, kappa and lambda variable and joining regions. Exp Clin Immunogenet 1999;16:234-240.

8 Folch G, Lefranc MP: The human T cell receptor beta variable (TRBV) genes. Exp Clin Immunogenet 2000; 17:42-54.

9 Scaviner D, Lefranc MP: The human $T$ cell receptor alpha variable (TRAV) genes. Exp Clin Immunogenet 2000;17:83-96.

10 Scaviner D, Lefranc MP: The human $\mathrm{T}$ cell receptor alpha joining (TRAJ) genes. Exp Clin Immunogenet 2000;17:97-106.

11 Folch G, Lefranc MP: The human T cell receptor beta diversity (TRBD) and beta joining (TRBJ) genes. Exp Clin Immunogenet 2000;17:107114.
12 Artéro S, Lefranc MP: The teleostei immunoglobulin heavy IGH genes. Exp Clin Immunogenet 2000;17: 148-161.

13 Artéro S, Lefranc MP: The teleostei immunoglobulin light IGL1 and IGL2 V, J and C genes. Exp Clin Immunogenet 2000;17:162-172.

14 Folch G, Scaviner D, Contet V, Lefranc MP: Protein displays of the human $\mathrm{T}$ cell receptor alpha, beta, gamma and delta variable and joining regions. Exp Clin Immunogenet 2000;17:205-215.

15 Lefranc MP, Giudicelli V, Ginestoux C, Bodmer J, Müller W, Bontrop R, Lemaître M, Malik A, Barbié V, Chaume D: IMGT, the international ImMunoGeneTics database. Nucleic Acids Res 1999;27: 209-212.

16 Ruiz M, Giudicelli V, Ginestoux C, Stoehr P, Robinson J, Bödmer J, Marsh S, Bontrop R, Lemaître M, Lefranc G, Chaume D, Lefranc MP. IMGT, the international ImMunoGeneTics database. Nucleic Acids Res 2000;28:219-221. 